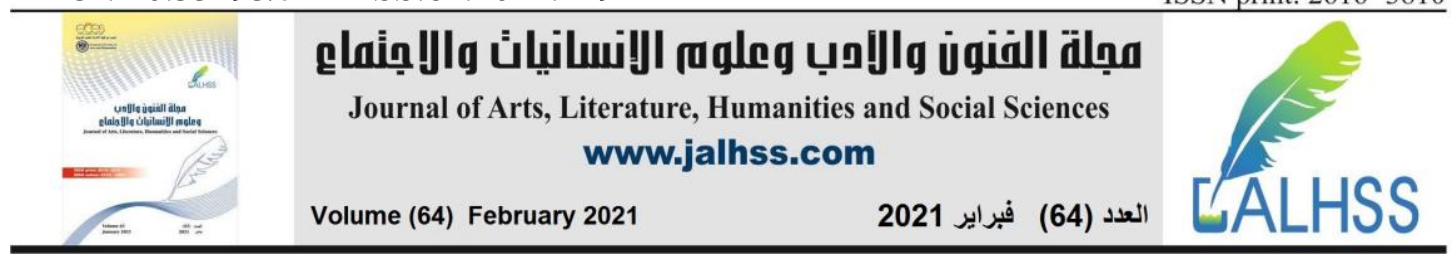

\title{
Possibility of using Art Forms in Interior Design
}

Mohammad Ahmad Bani Salameh

Luminus Technical University College, 11118 Amman, Jordan

Email: msalammeh@yahoo.com

\begin{abstract}
This study will discuss the possibility of using various art forms in interior design, as there was a significant impact, and aesthetic value via using artworks in interior design. The study has analyzed (5) design cases of artworks (sculpture, ceramics, painting, decoration, folk art) within an interior space concerning the added aesthetic value of these artworks in interior design. The study contained five cases to prove whether the use of these artworks added aesthetic value to interior design or not. The results have shown that artworks added an aesthetic, artistic and intellectual value to interior design.
\end{abstract}

Keywords: Interior Design, Art Forms, Artistic Value, Artworks. 


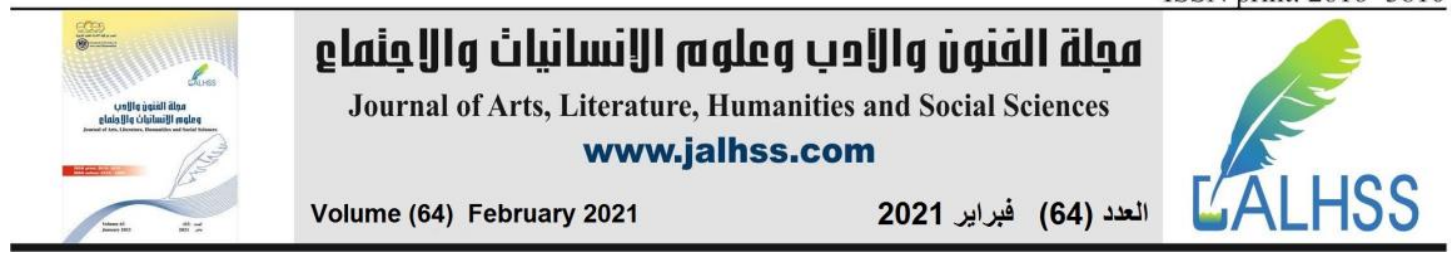

\section{Introduction:}

This era is characterized by the openness of all spheres to each other, and from these fields are arts, as there no boundaries that separate the arts from each other, such arts forms have merged together to form a single, integrated art painting and, this is the focus of our discussion in this study, where we will go through the combination of various art forms into interior design, which proves that art has no limits and can integrate with other fields and with different art forms, such as interior design, and this is the notion of this study

Interior design is a form of design that can be developed and aligned with other forms of design and arts within the customary design rules and foundations. Where functional and aesthetic value is the most prominent concern of interior design, and since we are talking about functional and aesthetic value, it also does not contingent with different art forms.

Arts in their various forms can complement and not be a burden on the functional and aesthetic aspect of interior design. and this pointed out by (Mahmoud.2011) that interior design is one form of arts that links between function and beauty,

and it may be the reason why this was created as a service that approaches to mastermind the objects and elements used in everyday life, proving this by using Islamic decorations in interior design as an aesthetic art performance.

This study will discuss the possibility of using various art forms such as sculpture, ceramics, painting and decorations in their different forms in line with the main values of interior design, which is aesthetic and functional.

\section{Problem Statement:}

Mohammad (2017) noted in his study the mechanism for analyzing Islamic decorative elements and add them into interior design and furniture and he pointed out through his study (Mahmoud, 2011) on the possibility of using the heritage Arab-Islamic arts in interior design. As Salama examined the intellectual dimensions of Islamic Art Which is represented by Islamic decoration (Salama, 2016). by showing Models of contemporary applications of useful products as an attempts to revive this magnificent heritage and benefited of its elements functionally and aesthetically through modern innovative visions

The study of (Fahmi \& Almomani, 2017) examines the possibility to achieve design indicators that will benefit in the use of aesthetics graffiti art in contemporary interior architecture and Saadi noted in his study about the flock Art and its implications on designing walls in interior spaces of houses an away to suit the needs of their users (Saadi \& Sultan, 2020). 


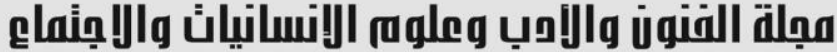

Journal of Arts, Literature, Humanities and Social Sciences

www.jalhss.com

Volume (64) February 2021

العدد (64) فبراير 2021

In a study of (Imam, 2018), he examined the most significant design values and considerations that can enrich the culture of intellectual perception through visual scenes used in interior spaces to reflect the meaning of privacy, identity, and sense of belonging

From previous studies we have not found any studies that have articulated the possibility of using various art forms in interior design.

This study is therefore being prominent for reviewing and studying the possibility of using various forms of plastic arts in interior design

\section{Methodology:}

This study has followed the descriptive and analytical a method to achieve of the aesthetic and artistic values of artworks through analyzing and describing artworks through design cases and identifying the impact of their use in interior design and to verify if it's integrated with interior design or not without confusing the overall design landscape to achieve the desired functional and aesthetic purpose of design.

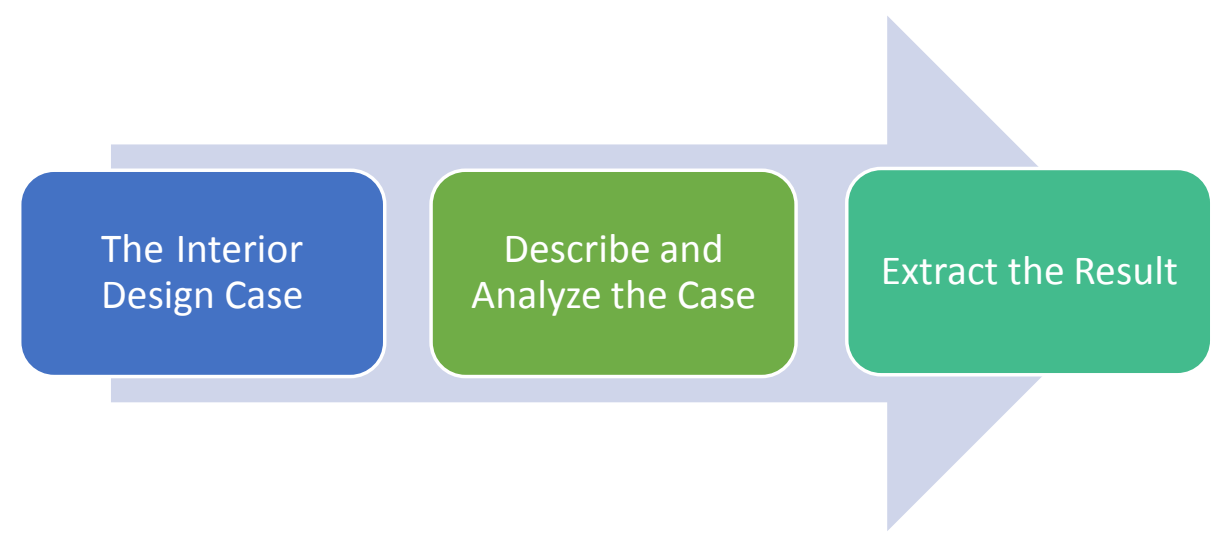

Figure 1: Descriptive Analytical Framework 


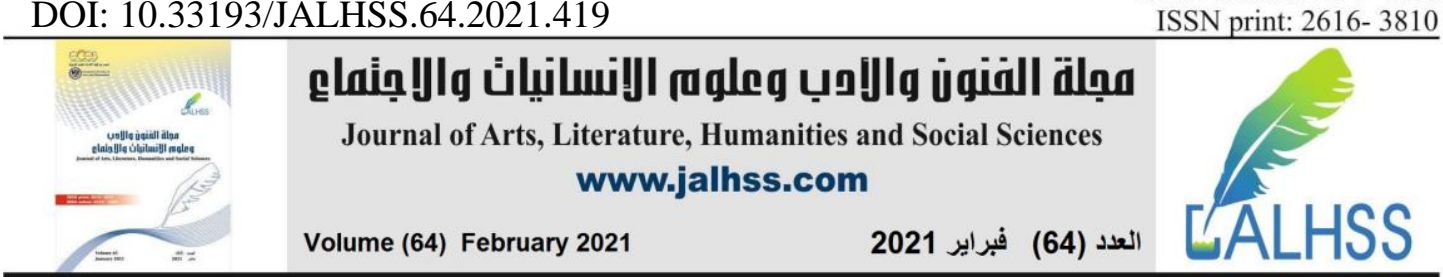

Case (1):

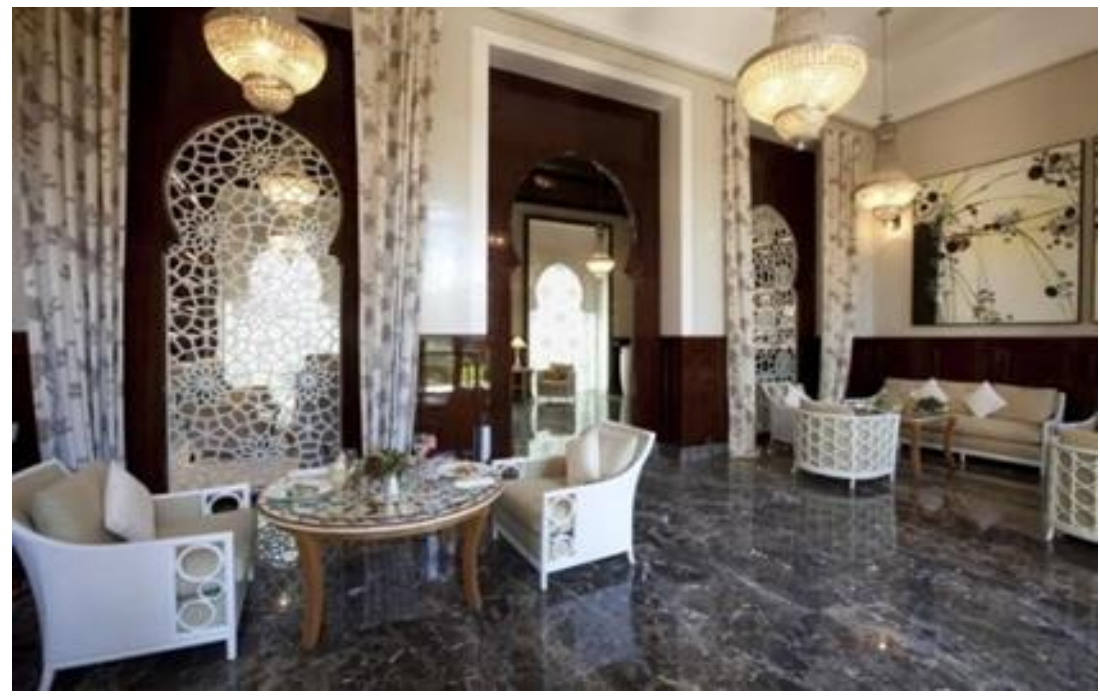

Picture (1): Geometric decorations in the lobby of the Royal Mansour Hotel Marrakech

Source: www.luxurydreamhotel.com

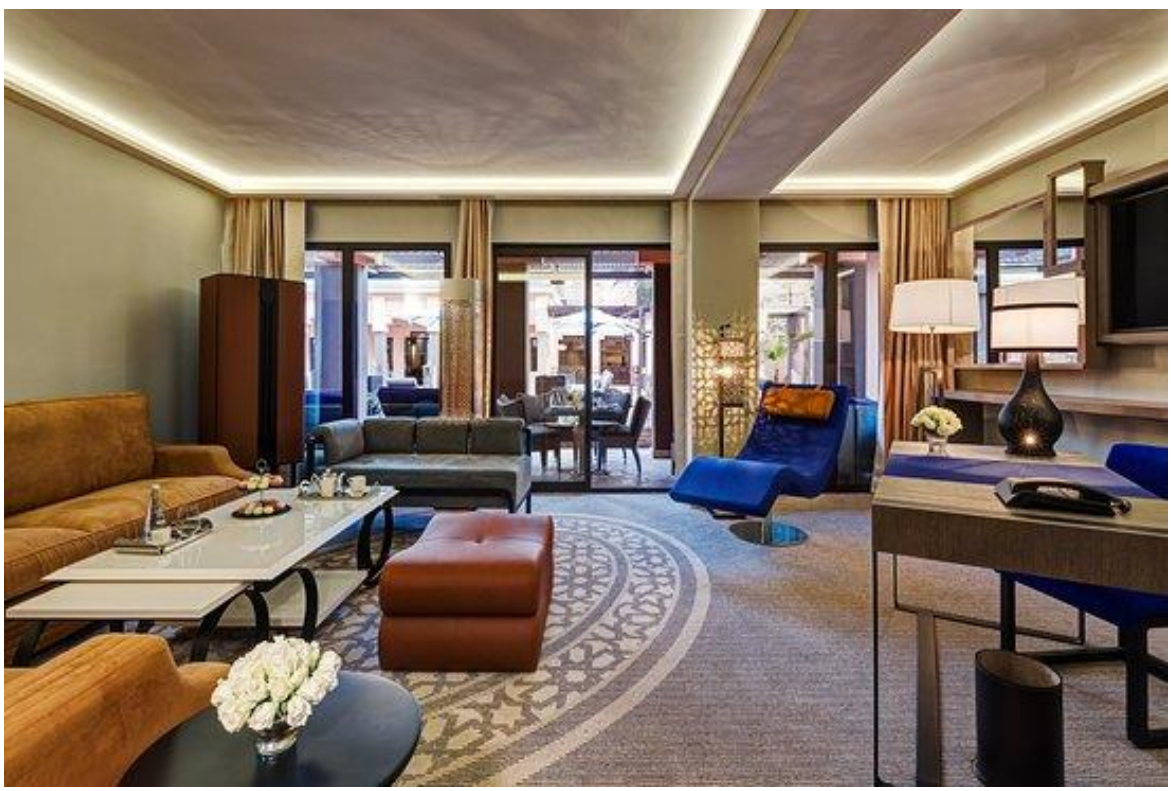

Picture (2): Geometric decorations on the floors of the Royal Mansour Hotel Marrakech, Morocco

Source: https://www.tripadvisor.fr. 


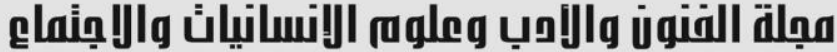 \\ Volume (64) February 2021 \\ العدد (64) فبراير 2021}

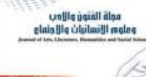

\section{Description:}

the hotel design of the entire hotel was inspired by the Islamic character, and the architecture of Islamic decorations was dominated the general design line. As we see a whole bunch of Islamic geometric decorations in the floors and walls and in the pieces of furniture integrated into each other to make for a great design scene.

\section{Analysis:}

Islamic art has been an inspiring source for designers to draw from their intellectual theses on contemporary designs with Islamic art features and the aesthetic of Islamic decorations. as It offers infinite solutions to contemporary designs and presents unique distinct ideas of authentic art proves this art a human-made art characterized by flexibility and fits every time and place

This model is one of the design proposals of contemporary designers to take advantage of the aesthetics of Islamic geometry (Salama, 2016)

The space has been characterized by many Islamic geometric decorations in walls and floors, as the design treatments for these decorations have clearly been shown by the place and the main theme of the hotel, which is the dominancy of the Islamic characters in the place.

This brings a sense of originality and contemporary at the same time, where the designer made these decorations in his design to present aesthetic value which is obvious in the place and corresponding the main theme of the hotel design, which is the dominancy of Islamic character.

\section{Case (2):}

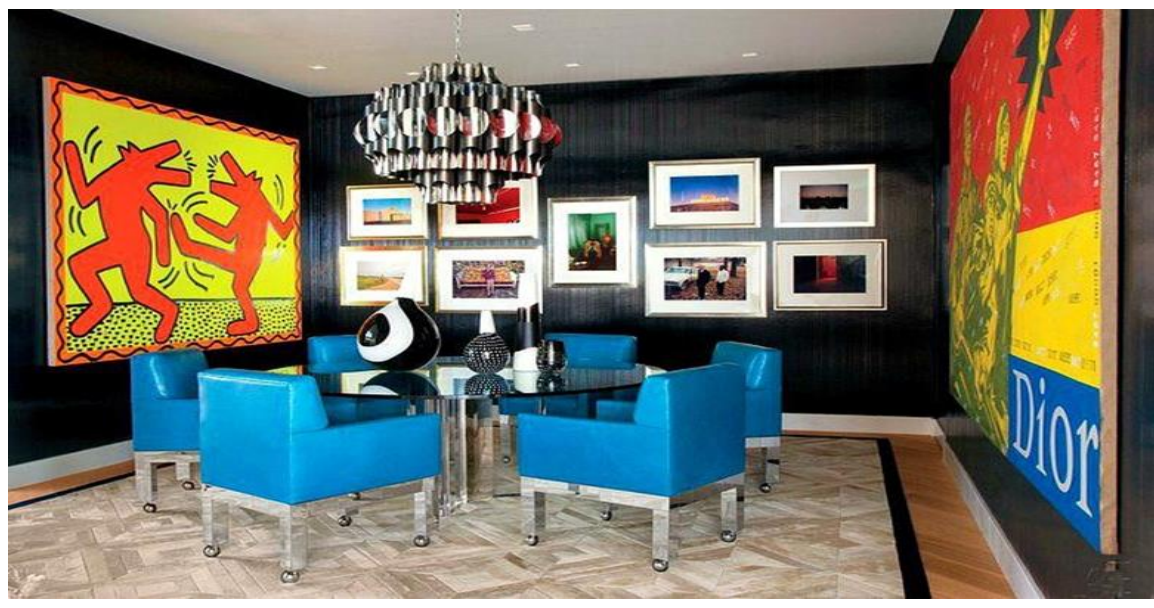

Picture (2): designed house by Bullard Lawrence Martyn (2012) Source: https://www.jalhss.com 


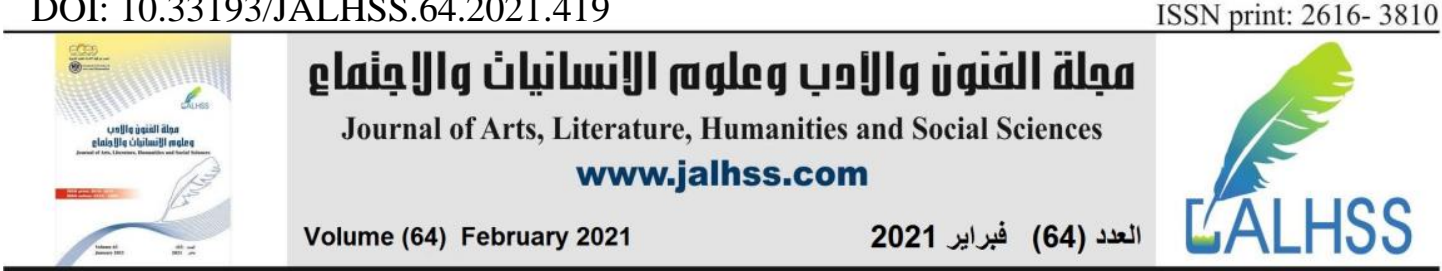

\section{Description:}

In 2012 this house was designed by the designer Martyn Lawrence Bullard in 2012 in Los Angeles, California, and has 1200 square feet. The owner of the house is an English singer-songwriter, pianist and author named John Elton. this space for dining has been painted black with a collection of photographic paintings and two large scale paintings representing artworks of the artists Keith Haring and Wang Guangini (Saadi \& Sultan, 2020).

\section{Analysis:}

This space was characterized by various sizes of paintings and images, where black was used as a background to highlight these paintings. Where Design treatments have been developed to highlight folk art in its concepts and specificity via excitement, thrilling, and strangeness, which are the characteristic of folk art and postmodern art, and it's really what we see in the design of this space, which is characterized by inconsistencies and contradictions, whether in the theme of paintings and images displayed on the walls or via colors being used in the place.

We see that these paintings integrated with the general design of the place through the strong, stark colors and conflicting artistic topics, which are consistent with the color of the walls and the pieces of furniture in the place, despite its strangeness, but its achieved the required purpose of it as main elements in the design through surprise and feeling strange.

\section{Case (3):}

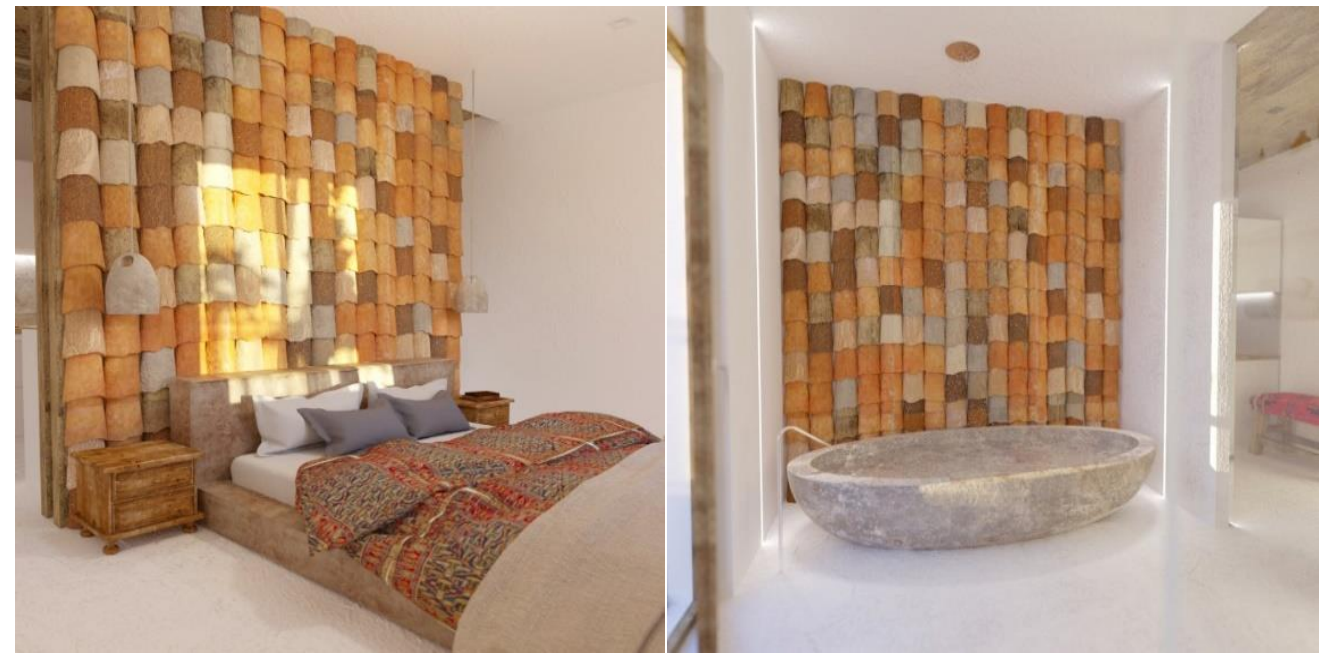

Picture (4): Hotel apartment in Bulgaria

Source: www.homeklondike.site 


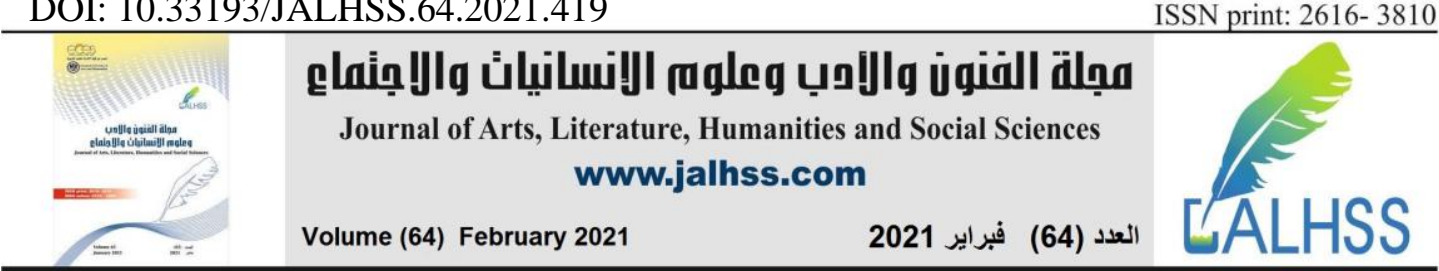

\section{Description:}

A hotel apartment with a ceramic mural on the bedroom wall and the bathroom, implemented using rooftop rinks, which is one of the most prevalent ceramics in Bulgaria (Homeklondike, 2017).

\section{Analysis:}

The design of the ceramic mural is compatible with the concepts of interior design of this hotel apartment, in which the designer expresses simplicity, and that is compatible with Bulgarian building traditions, where local colors of the same environment have been used, the walls have been lined with ceramics, which is one of the most widespread building materials in Bulgaria, and is perfectly consistent with the interior concept of the apartment. (Homeklondike, 2017). And that is what we see in this simple place with its tools and colors and its design, which in practice reflects the main idea of hotel design, the integration of the use of ceramic ore with colors and the simple design in order to achieve the desired aesthetic and functional values, to be a main element for the general design, this indicates the main role that this mural plays in the general design of the place.

\section{Case (4)}

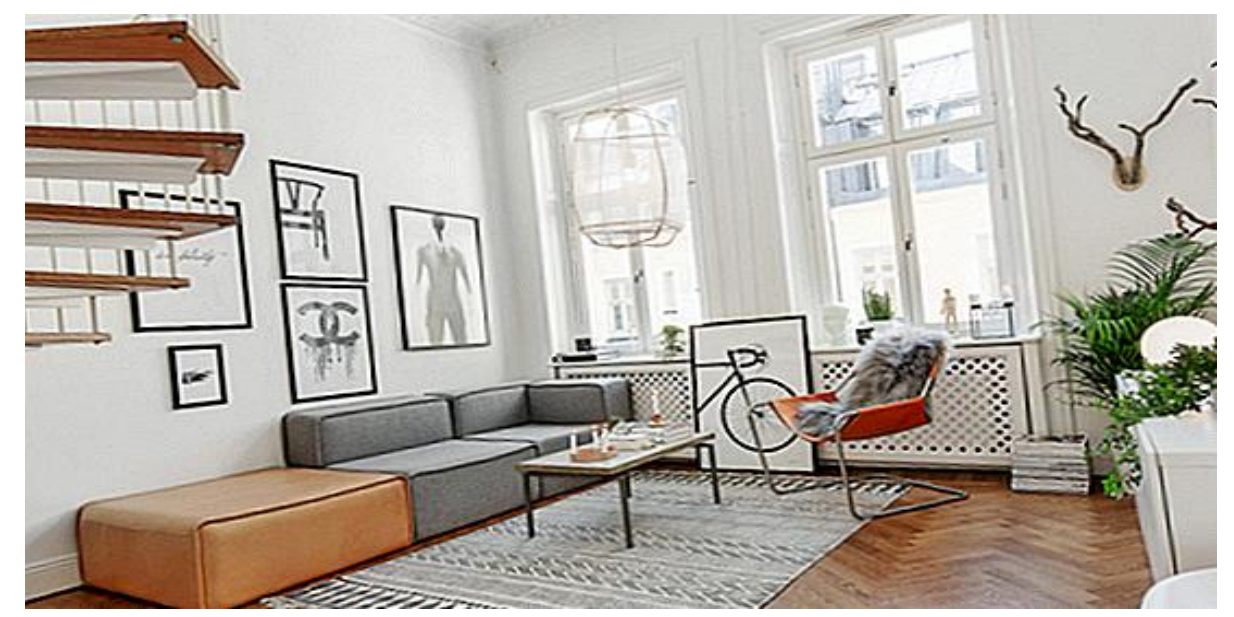

Picture (5): Scandinavian-style living room

Source: https://sy.aluzar.ru

\section{Description:}

The Scandinavian-style designer's living room has modern furniture and horns hanging on the wall, where it considered from the most prominent elements of the Scandinavian decorations in addition to wall paintings (Aluzar, 2019). 


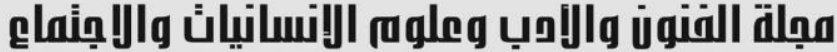 \\ Journal of Arts, Literature, Humanities and Social Sciences www.jalhss.com \\ Volume (64) February 2021 \\ العدد (64) فبراير 2021}

\section{Analysis:}

The Scandinavian style can become more "vibrant" by art pieces: Tire plates, deer horns on the wall, and wooden combinations on the control unit table (Aluzar, 2019).

And what we actually see is that the paintings on the wall were an aesthetic value added to the design, and complementary pieces to other design elements, such as furniture, where its lines went along with the lines of the simple pieces of furniture, without being a burden on the design, but necessary elements, to fill the vacuum that's not design-acceptable

\section{Case (5):}

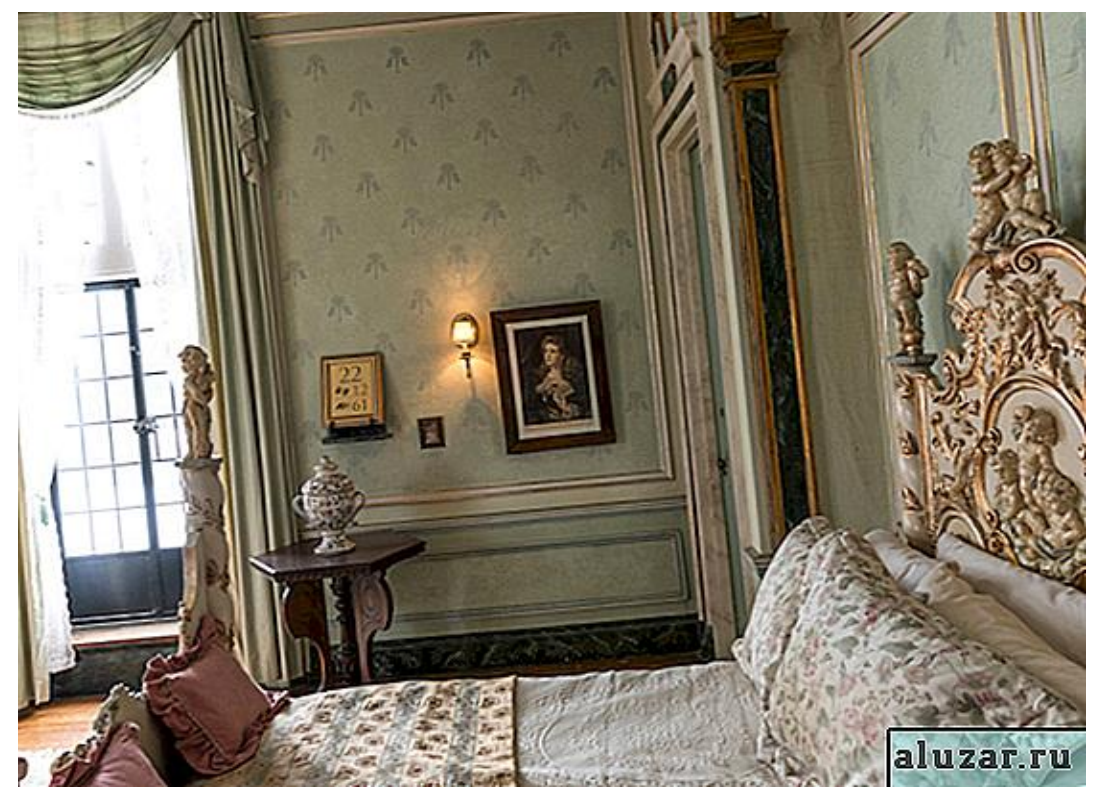

Picture (6): bedroom with classical style

Source: https: https://sy.aluzar.ru

\section{Description:}

A bedroom designed in the classical style, it contained various elements, such as a bed, a small table, and art pieces in the form of sculptures, a painting, and lights with marvelous and bronze colors (Aluzar, 2019).

\section{Analysis:}

The classical furniture pieces of the bedroom are a whole set, not a separate one. The bed (middle of the bedroom), a double bed, made of expensive rare wood, with a tall, dense carved front panel with often a large umbrella, everything in the room creates a luxurious effect, reinforced by the presence of elegant sculptures, marbled or bronze 


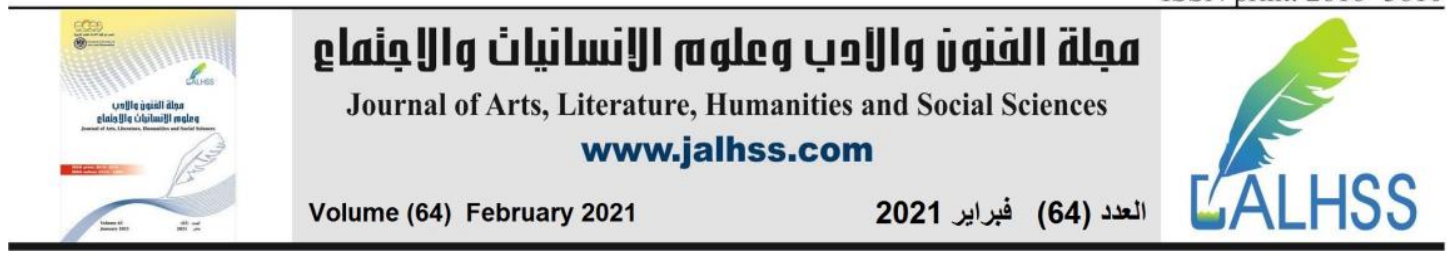

elements, a combination of dark and light colors that creates an extraordinary atmosphere of comfort in the room, and the center of composition is a huge bed with some sculptures (Aluzar, 2019).

The presence of sculptures in the room completed the classical character controlling the overall design of the room, and is one of the main design centers, if we look at the bedside, the classical sculptures and the sculptures on the front board, we understand how these elegant sculptures affects the overall design of the room, the aesthetic values, the elegance, the magnificence and the distinction that these sculptures added to the rest of the design elements

\section{Results:}

Aesthetic decoration and artwork are visual spices for an elegantly decorated interior decorations, and can highlight the best features of different elements if chosen with care and taste, so if you want to enrich your living area with art, you should be careful in choosing the right thing, to present an added value to the design and not be a burden on it, and this what the study aims at which is the possibility of using various art forms in interior design.

The results of the analysis of the design cases in which different art forms were used showed that the use of these forms (painting, carving, ceramic, ornamental, folk art) was an added value form and corresponded to the aesthetic purpose of the interior design of the places where it was used.

Artworks are really consistent with the interior design in terms of content and form, as a result, the artwork is no longer separated or isolated from its surroundings, it's part of the place where it's existed, and it has to get along with it, whether it's a bedroom or a living room, or in anywhere it existed.

\section{References}

1- Mohammad, S. I. (2017). Interior Design and Furniture through a Contemporary Vision of Geometrical Analysis of Islamic Ornamental Units. International Design Journal, 1, 1-31. Retrieved from https://www.faadesign.com/conf/pdf/conf4/4 .pdf.

2- Mahmoud, S. A. (2011). Decorative Elements in the Interior Design of the AlMustansiriya School: An Analytical Descriptive Study (Unpublished master's thesis). The World Islamic Sciences University. doi:https://ia801006.us.archive.org/12/items/ktp2019-tra7786/ktp2019tra7786.pdf.

3- Salama, H. M. (2016). Aesthetics geometric shape in Islamic arts and its modern applications. Architecture and Arts Journal, 3, 1-15. Retrieved January 18, 2021, 


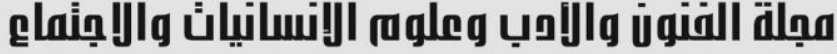

Journal of Arts, Literature, Humanities and Social Sciences

www.jalhss.com

Volume (64) February 2021

العدد (64) فبراير 2021

from https://mjaf.journals.ekb.eg /article_20516_5421bd218e 73756351 50f45f 16ae6ed6.pdf.

4- Fahmi, M., \& Almomani, W. (2017). The Aesthetics of Graffiti Art in the Contemporary Interior Space. Jordanian Journal of Arts, 10(1), 35-48. Retrieved January 18, 2021, from http://journals .yu.edu.jo/jja/ JJAIssues/ Vol10Nom 12017 /Nom3.pdf.

5- Saadi, H. F., \& Sultan, K. A. (2020). Pop Art and Their Reflection on Walls Design in the Interior Spaces. Journal of Arts, Literature, Humanities and Social Science, 52, 279-301. Retrieved January 18, 2021, from http://www.jalhss.com/index.php/ jalhss/article/view/90/83.

6- Imam, A. (2018). Visual arts and a culture of meaning in interior design. In The Fourth International Conference on Plastic Arts and Community Service. Luxor: South Valley University.

8- Homeklondike. (2017, July 28). Close-to-Nature Holiday Residence in Sunny Bulgaria. Retrieved January 18, 2021, from http://homeklondike.site /2017/07/2 8/close-to-nature-holiday-residence-in-sunny-bulgaria/.

9- Aluzar. (2019). Bedrooms in classic style. Aluzar. Retrieved January 18, 2021, from https://sy.aluzar.ru/1027-classic-style-bedrooms-75-photos-luxury-shineand-co.html.

10- https://www.tripadvisor.fr/LocationPhotoDirectLink-g293734-d302479i228477426. 